\title{
PENGARUH GAYA KOMUNIKASI PIMPINAN TERHADAP KINERJA KARYAWAN BIDANG KOMPONEN TREATMEN DI PT. BINTANG INDOKARYA GEMILANG BREBES
}

\author{
Nuralim, Yusup Sapari, Muhammad Kamaludin, Lisna Novita \\ Email: alimnur2812@gmail.com, ysapari73@gmail.com, \\ m.kamaluddin@umc.ac.id, lisnanovita29@gmail.com \\ Ilmu Komunikasi, Fakultas Ilmu Sosial dan Ilmu Politik \\ Universitas Muhammadiyah Cirebon \\ Jl Fatahillah No.40, Watubelah, Sumber, Cirebon \\ Submitted: 20 Februari 2021| Accepted: 24 Maret 2021 | Published: 30 Juni 2021 \\ Website: https://e-journal.umc.ac.id/index.php/jike/index
}

\begin{abstract}
The success of a leader in directing his subordinates to produce performance cannot be separated from the organizational communication climate conditions that encourage the achievement of such performance. The communication made by the leader to his employees will be a bridge for the leader to be able to provide improvements to the performance of the team he leads.

This study aims to determine the effect of leadership communication style on employee performance in the Component Gtreatment sector at PT Bintang Indokarya Gemilang Brebes. This research uses an explanative quantitative method. The population in this study were 195 employees of PT Bintang Indokarya Gemilang Brebes in the Component Treatment Sector. The sampling technique used is purposive sampling and obtained a sample of 66 people. Data collection in this study used a questionnaire distributed using a google form link. The tests carried out are Normality Test and Linearity Test. The hypothesis test used is simple linear regression.

The results in this study can be concluded: Leadership Communication Style positively affects Employee Performance. The amount of Communication Style influence on employee performance was $0.753(75.3 \%)$. And obtained adjusted $R$ Squere results of 0.382 or $38.2 \%$ this shows that employee performance variables are influenced by the variable leadership communication style of $38.2 \%$ while the remaining $61.8 \%$ is influenced by other factors beyond those discussed in this study.
\end{abstract}

Keywords: Communication, Leadership Communication Style, Employee Performance, TLI (Transformational Leadership Inventory).

\begin{abstract}
ABSTRAK
Keberhasilan seorang pemimpin dalam mengarahkan bawahannya untuk menghasilkan kinerja tidak lepas dari kondisi iklim komunikasi organisasi yang mendorong pencapaian kinerja tersebut. Komunikasi yang dilakukan pemimpin terhadap karyawannya akan menjadi suatu jembatan bagi pemimpin agar dapat memberikan peningkatan terhadap kinerja tim yang dipimpinnya.

Penelitian ini bertujuan untuk mengetahui Pengaruh Gaya Komunikasi Pimpinan Terhadap Kinerja Karyawan Bidang Component Gtreatment di PT Bintang Indokarya Gemilang Brebes. Penelitian ini menggunakan metode kuantitaf eksplanatif. Populasi dalam penelitian ini sebanyak 195 karyawan PT Bintang Indokarya Gemilang Brebes Bidang Component Treatment. Teknik sampel yang digunakan adalah Purposive Sampling dan didapat sampel sebanyak 66 orang. Pengumpulan data pada penelitian ini menggunakan anket yang disebar menggunakan link google form. Uji yang dilakukan adalah Uji Normalitas dan Uji Linieritas. Uji Hipotesis yang digunakan adalah regresi linier sederhana.
\end{abstract}


Hasil dalam penelitian ini dapat disimpulkan: Gaya Komunikasi Pimpinan berpengarus secara Positif terhadap Kinerja Karyawan. Besarnya pengaruh Gaya Komunikasi terhadap Kinerja karyawan adalah sebesar 0,753(75,3\%). Dan diperoleh hasil Adjusted R Squere sebesar 0,382 atau 38,2\% hal ini menunjukan bahwasanya variabel kinerja karyawan dipengaruhi oleh variabel gaya komunikasi pimpinan sebesar 38,2\% sedangkan sisanya yaitu 61,8\% dipengaruhi oleh faktor lain di luar yang dibahas dalam penelitian kali ini.

Kata Kunci: Komunikasi, Gaya Komunikasi Pimpinan, Kinerja Karyawan , TLI (Transformational Leadership Inventory)

\section{PENDAHULUAN}

Perusahaan dituntut memiliki sumber daya manusia yang mampu berkembang dan memiliki kemampuan yang handal. Demi menjalankan roda perusahaan secara efektif, produktif dan profesional, perusahaan dituntut untuk menyesuaikan diri secara terus menerus dalam melakukan sebuah perubahan dan perbaikan. Faradina (2017) mengungkapkan dalam menunjang kesuksesan, perusahaan harus mampu memberikan stimulasi yang tinggi bagi sumber daya manusianya agar mampu menciptakan keharmonisan dalam suatu perusahaan.

Perusahaan yang maju dan berkembang akan memiliki sumber daya manusia yang mampu menghadapi era globalisasi, yang dimana sebuah perusahaan akan mampu bersaing secara kompleks dan kompetitif. Sumber daya manusia yang dimiliki perusahaan terpeta oleh adanya struktur keorganisasian ataupun struktur kepegawaian yang di dalamnya terdapat pemimpin yang menjadi kepala yang akan mempengaruhi Sumber daya manusia yang dipimpinnya yang disebut juga sebagai kepemimpinan.

Kepemimpinan adalah suatu proses atau gaya seseorang untuk mempengaruhi orang lain agar orang tersebut mengikuti apa yang diperintahkan oleh pemimpin. Dalam mempengaruhi orang lain, pemimpin akan menggunakan komunikasi yang akan di terapkan, komunikasi yang diterapkan akan memiliki masing-masing gaya yang berbeda di setiap karakter pemimpinnya. Komunikasi yang dilakukan pemimpin terhadap karyawannya akan menjadi suatu jembatan bagi pemimpin agar dapat memberikan peningkatan terhadap kinerja tim yang dipimpinnya.

Sejalan dengan fenomena ini, gaya komunikasi pimpinan terhadap kinerja karyawan sangat menentukan kesuksesan sebuah perusahaan. Widha Mandasari (2017) berpendapat, atasan memegang peranan penting dalam menumbuhkan motivasi bagi karyawannya karena jika tidak ada dorongan maka karyawan tidak dapat memotivasi diri sendiri untuk lebih meningkatkan kinerjanya. 
Penelitian sebelumnya yang relevan dengan penelitia ini adalah Pertama, Fahri Husaini (2019) yang mengkaji tentang Pengaruh gaya kepemimpinan dan Kepuasan kerja terhadap kinerja pegawai pada satuan polisi pamong praja kabupaten Cirebon. Kedua, Faradhina Mauina Fitria (2017, melakukan penelitian tentang Pengaruh ggaya kominikasi terhadap kinerja karyawan Bank Tabunga Negara Kantor Kas cabang Pemuda, Surabaya. Ketiga, M Kiswanto (2010) mengkaji tentang Pengaruh Kepemimpinan dan Komunikasi Terhadap Kinerja karyawan Kaltim Pos Samarinda. Keempat, Erick Novalino Darmawan melakukan penelitian tentang Pengaruh Gaya komunikasi dan gaya kepemimpinan terhadap kinerja karyawan dengan gaya kepemimpinan sebagau intervening variabel. Kelima, Darlena Helensi yang melakukan penelitian tentang Pengaruh gaya komunikasi pimpinan terhadap kinerja Pegawai ( Pada Dinas Pariwisata dan Dinas Sosial Kota Bengkulu ).

Metode penelitian yang digunakan dalam penelitian ini adalah metode kuantitatif dengan jenis atau tipe eksplanatif. Teknik sampel yang digunakan adalah Purposive Sampling dan didapat sampel sebanyak 66 orang. Pengumpulan data pada penelitian ini menggunakan anket yang disebar menggunakan link google form. Uji yang dilakukan adalah Uji Normalitas dan Uji Linieritas. Uji Hipotesis yang digunakan adalah regresi linier sederhana.

Penelitian ini berlokasi di PT. Bintang Indokarya Gemilang yang beralamat di, Jl. Cendrawasih No. 6 Km 20 Desa tengguli, kec. Tanjung kab. Brebes, Jawa Tengah 52254. Populasi dalam penelitian ini sebanyak 195 karyawan PT Bintang Indokarya Gemilang Brebes Bidang Component Treatment. Dalam perjalanannya Divisi component treatmen mengalami beberapa kali pergantian pemimpin, terhitung tahun 2017-2019 yang dimana setiap pemimpinnya memiliki gaya komunikasi tersendiri dalam memimpin Divisi tersebut. Pimpinan divisi component treatmen yang saat ini memiliki gaya komunikasi yang humanis terhadap karyawannya. Dimana pimpinan sekarang lebih banyak mendengar apa yang yang dibutuhkan oleh karyawan karena dalam berjalannya produksi karyawanlah yang faham dan mengetahui apa saja yang dibutuhkan di lapangan agar proses produksi bisa berjalan dengan baik dan mencvapai target yang diinginkan .

Berdasarkan penjelasan yang telah diuraikan, menarik dan penting untuk dilakukan sebuah penelitian tentang Pengaruh Gaya Komunikasi Pimpinan terhadap Kinerja Karyawan Component Treatment PT. Bintang Indokarya Gemilang. 


\section{HASIL DAN PEMBAHASAN}

PT. Bintang Indokarya Gemilang yang merupakan anak perusahaan PT. Panarub Industry yang terletak di Desa Tengguli, Kecamatan Tanjung, Kabupaten Brebes. PT. Bintang Indokarya Gemilang adalah salah satu pabrik produsen sepatu Adidas dan merupakan anak perusahaan PT. Panarub Industry yang berada di wilayah Kabupaten Brebes dengan skala yang besar. Panarub ditunjuk sebagai Football Center khusus brand Adidas dan sekarang dipimpin oleh putra Bapak Lucas, Hendrik Sasmito. Panarub telah berkembang menjadi 25 lini produksi berteknologi tinggi dengan lebih dari 11.000 karyawan yang memproduksi sepatu profesional berkualitas untuk para atlet di seluruh dunia.

Penelitian mengenai pengaruh gaya komunikasi pimpinan terhadap kinerja karyawan akan dilakukan pada divisi component treatment di PT Bintang Indokarya Gemilang Brebes karena pada divisi ini mengalami pergantian pimpinan setara manager didalam divisi component treatment pada tahun 2019. Divisi component treatment berperan membuat gambar dalam lembaran material siap produksi untuk di Printing atau di sablon sesuai dengan model yang dibutuhkan dalam memenuhi stok barang yang akan dikirim dibagian Sewing dan Assembling untuk di rakit menjadi sepatu. Dalam perjalanannya Divisi component treatmen mengalami beberapa kali pergantian pemimpin, terhitung tahun 2017-2019 yang dimana setiap pemimpinnya memiliki gaya komunikasi tersendiri dalam memimpin Divisi tersebut.

Maka untuk dapat mengetahui bagaimana Pengaruh Gaya Komunikasi Pimpinan Terhadap Kinerja Karyawan Bidang Component Treatment Di PT Bintang Indokarya Gemilang Brebes penelitian ini memfokuskan ke dalam pembahasan pengaruh Gaya Komunikasi pimpinan terhadap kinerja karyawan dan kinerja karyawan bidang component treatment di PT Bintang Indokarya Gemilang.

Deskripi atas jawaban responden pada kuisioner ini digunakan untuk mengukur variabel gaya komunikasi dan kinerja karyawan, dimana jawaban tersebut diukur menggunakan skala liker 1-5 yang dibagikan kepada 66 orang responden. Teknik dalam mengukur frekuensi skor jawaban digunakan untuk melihat penyajian jawaban responden. Yang kemudian digunakan untuk melihat dan menginterpretasikan kecenderungan jawaban responden terhadap setiap item pertanyaan. Berikut rumus untuk melihat panjang interval: 


$$
\mathrm{p} \frac{\text { Rentang }}{\text { banyak kelas }}
$$

Penjelasan;

$\mathrm{P}$

: Panjang Kelas interval

Rentang

: Data terbesar - Data terkecil

Banyak Kelas

: 5 berdasarkan Rumus diatas

Untuk mengetahu panjang intervalnya sebagai berikut:

$$
P \frac{5-1}{5}=0,8
$$

Tabel Pengukuran Skor

\begin{tabular}{|l|l|}
\hline Kategori & Nilai \\
\hline Sangat baik & $4,20-5,00$ \\
\hline Baik & $3,40-4,19$ \\
\hline Sedang & $2,60-3.39$ \\
\hline Rendah & $1,80-2,59$ \\
\hline Sangat rendah & $1,00-1,78$ \\
\hline
\end{tabular}

Data yang diperoleh dari koresponden yang mengisi kuisioner penelitian ini berisikan tentang karateristik responden yaitu, usia, jenis kelamin, lamanya bekerja, dan jabatan. Data yang sudah didapat dioleh menggunakan aplikasi statistik IBM SPSS 26.

Hasil yang didapat dari penelitian ini adalah dimana. Nilai $t_{\text {hitung }}$ sebesar 6,418 dan mendapatkan nilai sig sebesar 0,000. Nilai uji $t_{\text {hitung }}$ tersebut lebih besar daripada $t_{\text {tabel }}(6,418>0,2423)$ dan memiliki nilai sig. $0,000<0,05$. Maka dapat disimpulkan pada penelitian ini bahwa variabel indenpenden gaya komunikasi pimpinan berpengaruh signifikan terhadap variabel dependen kinerja karyawan.

\section{Rekapitulasi Responden dan Rata Skor Variabel Gaya Komunikasi}




\begin{tabular}{|c|c|c|c|c|c|c|c|c|}
\hline \multirow{2}{*}{ NO } & \multirow{2}{*}{$\begin{array}{l}\text { Pertanyaan Variabel Gaya } \\
\text { komunikasi }(\mathrm{X})\end{array}$} & \multicolumn{3}{|c|}{$\begin{array}{l}\text { Frekuensi } \\
\text { Responden }\end{array}$} & \multicolumn{2}{|c|}{ Jawaban } & \multirow{2}{*}{$\begin{array}{l}\text { Total } \\
\text { responden }\end{array}$} & \multirow{2}{*}{$\begin{array}{l}\text { Nilai } \\
\text { Rata- } \\
\text { Rata }\end{array}$} \\
\hline & & $\begin{array}{l}\text { SS } \\
(5)\end{array}$ & $\begin{array}{l}S \\
(4)\end{array}$ & $\begin{array}{l}\mathbf{R R} \\
(3)\end{array}$ & $\begin{array}{l}\text { TS } \\
(2)\end{array}$ & $\begin{array}{l}\text { STS } \\
\text { (1) }\end{array}$ & & \\
\hline 1 & $\begin{array}{l}\text { Saya dapat memahami } \\
\text { arahan yang diberikan oleh } \\
\text { pompinan (Manager) }\end{array}$ & 23 & 34 & 8 & 1 & 0 & 66 & 4,20 \\
\hline 2 & $\begin{array}{l}\text { Saya mudah berkomunikasi } \\
\text { dengan baik jika pimpinan } \\
\text { penyampaian informasi yang } \\
\text { baik }\end{array}$ & 22 & 39 & 4 & 1 & 0 & 66 & 4,24 \\
\hline 3 & $\begin{array}{l}\text { Saya langsung mengerti jika } \\
\text { pimpinan (Manager) } \\
\text { memberikan perintah }\end{array}$ & 13 & 41 & 9 & 3 & 0 & 66 & 3,97 \\
\hline 4 & $\begin{array}{l}\text { Saya merasa nyaman dalam } \\
\text { menyelesaikan tugas karena } \\
\text { diberikan fasilitas yang } \\
\text { memadai }\end{array}$ & 13 & 32 & 13 & 6 & 2 & 66 & 3,73 \\
\hline 5 & $\begin{array}{l}\text { Saya dapat bekerja dengan } \\
\text { baik karena kebutuhan } \\
\text { tempat kerja yang } \\
\text { memuaskan }\end{array}$ & 12 & 31 & 16 & 6 & 1 & 66 & 3,71 \\
\hline 6 & $\begin{array}{l}\text { Saya mampu memberikan } \\
\text { hasil kerja secara maksimal }\end{array}$ & 17 & 41 & 8 & 0 & 0 & 66 & 4,14 \\
\hline 7 & $\begin{array}{l}\text { Saya dapat mengerjakan } \\
\text { tugas dengan tepat waktu }\end{array}$ & 12 & 44 & 10 & 0 & 0 & 66 & 4,03 \\
\hline 8 & $\begin{array}{l}\text { Saya mendapat dorongan } \\
\text { dari pimpinan (Manager) } \\
\text { untuk menyelesaikan } \\
\text { pekerjaan }\end{array}$ & 11 & 40 & 12 & 2 & 1 & 66 & 3,88 \\
\hline 9 & $\begin{array}{l}\text { Saya mendapat bimbingan } \\
\text { dengan baik untuk }\end{array}$ & 13 & 35 & 10 & 8 & 0 & 66 & 3,8 \\
\hline
\end{tabular}




\begin{tabular}{|c|c|c|c|c|c|c|c|c|}
\hline & $\begin{array}{l}\text { menyelesaikan tugas oleh } \\
\text { pimpinan (Manager) }\end{array}$ & & & & & & & \\
\hline 10 & $\begin{array}{l}\text { Saya dapat bertanggung } \\
\text { jawab atas fasilitas yang di } \\
\text { dapatkan dalam lingkungan } \\
\text { kantor }\end{array}$ & 14 & 43 & 8 & 1 & 0 & 66 & 4,06 \\
\hline 11 & $\begin{array}{l}\text { Saya mendapatkan stimulasi } \\
\text { terlebih dahulu jika dalam } \\
\text { pemberian tugas }\end{array}$ & 6 & 40 & 14 & 6 & 0 & 66 & 3,70 \\
\hline 12 & $\begin{array}{l}\text { Saya selalu merasa puas } \\
\text { dengan hasil kerja yang telah } \\
\text { dikerjakan }\end{array}$ & 14 & 44 & 7 & 1 & 0 & 66 & 4,08 \\
\hline \multicolumn{8}{|c|}{ Total Rata Rata } & 3,96 \\
\hline \multirow{2}{*}{ NO } & \multirow{2}{*}{$\begin{array}{l}\text { Pertanyaan Variabel Gaya } \\
\text { komunikasi }(\mathrm{X})\end{array}$} & \multicolumn{3}{|c|}{$\begin{array}{l}\text { Frekuensi } \\
\text { Responden }\end{array}$} & \multicolumn{2}{|c|}{ Jawaban } & \multirow{2}{*}{$\begin{array}{l}\text { Total } \\
\text { responden }\end{array}$} & \multirow{2}{*}{$\begin{array}{l}\text { Nilai } \\
\text { Rata- } \\
\text { Rata }\end{array}$} \\
\hline & & $\begin{array}{l}\text { SS } \\
(5)\end{array}$ & $\begin{array}{l}\text { S } \\
(4)\end{array}$ & $\begin{array}{l}\mathbf{R R} \\
\text { (3) }\end{array}$ & $\begin{array}{l}\text { TS } \\
(2)\end{array}$ & $\begin{array}{l}\text { STS } \\
\text { (1) }\end{array}$ & & \\
\hline 1 & $\begin{array}{l}\text { Saya dapat memahami } \\
\text { arahan yang diberikan oleh } \\
\text { pompinan (Manager) }\end{array}$ & 23 & 34 & 8 & 1 & 0 & 66 & 4,20 \\
\hline 2 & $\begin{array}{l}\text { Saya mudah berkomunikasi } \\
\text { dengan baik jika pimpinan } \\
\text { penyampaian informasi yang } \\
\text { baik }\end{array}$ & 22 & 39 & 4 & 1 & 0 & 66 & 4,24 \\
\hline 3 & $\begin{array}{l}\text { Saya langsung mengerti jika } \\
\text { pimpinan (Manager) } \\
\text { memberikan perintah }\end{array}$ & 13 & 41 & 9 & 3 & 0 & 66 & 3,97 \\
\hline 4 & $\begin{array}{l}\text { Saya merasa nyaman dalam } \\
\text { menyelesaikan tugas karena }\end{array}$ & 13 & 32 & 13 & 6 & 2 & 66 & 3,73 \\
\hline
\end{tabular}




\begin{tabular}{|c|c|c|c|c|c|c|c|c|}
\hline & $\begin{array}{l}\text { diberikan fasilitas yang } \\
\text { memadai }\end{array}$ & & & & & & & \\
\hline 5 & $\begin{array}{l}\text { Saya dapat bekerja dengan } \\
\text { baik karena kebutuhan } \\
\text { tempat kerja yang } \\
\text { memuaskan }\end{array}$ & 12 & 31 & 16 & 6 & 1 & 66 & 3,71 \\
\hline 6 & $\begin{array}{l}\text { Saya mampu memberikan } \\
\text { hasil kerja secara maksimal }\end{array}$ & 17 & 41 & 8 & 0 & 0 & 66 & 4,14 \\
\hline 7 & $\begin{array}{l}\text { Saya dapat mengerjakan } \\
\text { tugas dengan tepat waktu }\end{array}$ & 12 & 44 & 10 & 0 & 0 & 66 & 4,03 \\
\hline 8 & $\begin{array}{l}\text { Saya mendapat dorongan } \\
\text { dari pimpinan (Manager) } \\
\text { untuk menyelesaikan } \\
\text { pekerjaan }\end{array}$ & 11 & 40 & 12 & 2 & 1 & 66 & 3,88 \\
\hline 9 & $\begin{array}{l}\text { Saya mendapat bimbingan } \\
\text { dengan baik untuk } \\
\text { menyelesaikan tugas oleh } \\
\text { pimpinan (Manager) }\end{array}$ & 13 & 35 & 10 & 8 & 0 & 66 & 3,8 \\
\hline 10 & $\begin{array}{l}\text { Saya dapat bertanggung } \\
\text { jawab atas fasilitas yang di } \\
\text { dapatkan dalam lingkungan } \\
\text { kantor }\end{array}$ & 14 & 43 & 8 & 1 & 0 & 66 & 4,06 \\
\hline 11 & $\begin{array}{l}\text { Saya mendapatkan stimulasi } \\
\text { terlebih dahulu jika dalam } \\
\text { pemberian tugas }\end{array}$ & 6 & 40 & 14 & 6 & 0 & 66 & 3,70 \\
\hline 12 & $\begin{array}{l}\text { Saya selalu merasa puas } \\
\text { dengan hasil kerja yang telah } \\
\text { dikerjakan }\end{array}$ & 14 & 44 & 7 & 1 & 0 & 66 & 4,08 \\
\hline \multicolumn{8}{|c|}{ Total Rata Rata } & 3,96 \\
\hline
\end{tabular}


Berdasarkan pada tabel diatas bisa di interpretasikan bahwasanya variabel gaya komunikasi pimpinan component treatment di PT bintang Indokarya Gemilang Brebes baik, dimana bisa dilihat nilai total rata rata per item adalah 3,96\%. Berdasarkan pada tabel 4.5 pengukuran skor, nilai $3,96 \%$ berada di rentang skor $3,40-4,19$. Sehingga dapat disimpulkan Variabel Gaya Komunikasi Pimpinan di PT Bintang Indokarya Gemilang Brebes adalah baik.

Rekapitulasi Responden dan Rata Skor Variabel Kinerja Karyawan

\begin{tabular}{|c|c|c|c|c|c|c|c|c|}
\hline \multirow{2}{*}{ NO } & \multirow{2}{*}{$\begin{array}{l}\text { Pertanyaan Variabel } \\
\text { Kinerja Kayawan }(\mathbf{Y})\end{array}$} & \multicolumn{5}{|c|}{ Frekuensi Jawaban Responden } & \multirow{2}{*}{$\begin{array}{l}\text { Total } \\
\text { responden }\end{array}$} & \multirow{2}{*}{$\begin{array}{l}\text { Nilai } \\
\text { Rata- } \\
\text { Rata }\end{array}$} \\
\hline & & $\begin{array}{l}\text { SS } \\
(5)\end{array}$ & $\begin{array}{l}S \\
(4)\end{array}$ & $\begin{array}{l}\text { RR } \\
\text { (3) }\end{array}$ & $\begin{array}{l}\text { TS } \\
(2)\end{array}$ & $\begin{array}{l}\text { STS } \\
\text { (1) }\end{array}$ & & \\
\hline 1 & $\begin{array}{l}\text { Saya mampu mengerjakan } \\
\text { lebih dari satu pekerjaan }\end{array}$ & 7 & 44 & 12 & 3 & 0 & 66 & 3,83 \\
\hline 2 & $\begin{array}{l}\text { Saya selalu merasa puas } \\
\text { dengan hasil kerja yang telah } \\
\text { dikerjakan }\end{array}$ & 8 & 43 & 13 & 2 & 0 & 66 & 3,86 \\
\hline 3 & $\begin{array}{l}\text { Saya melaksanakan pekerjaan } \\
\text { sesuai dengan standar } \\
\text { operasional perusahaan (SOP) }\end{array}$ & 19 & 41 & 6 & 0 & 0 & 66 & 4,20 \\
\hline 4 & $\begin{array}{l}\text { Saya pernah mendapatkan } \\
\text { predikat sebagai karyawan } \\
\text { terbaik }\end{array}$ & 4 & 13 & 23 & 24 & 2 & 66 & 2,89 \\
\hline 5 & $\begin{array}{l}\text { Karena pendidikan yang saya } \\
\text { tempuh sebelumnya saya } \\
\text { dapat memahami setiap } \\
\text { pekerjaan saya }\end{array}$ & 5 & 42 & 15 & 4 & 0 & 66 & 3,73 \\
\hline
\end{tabular}




\begin{tabular}{|c|c|c|c|c|c|c|c|c|}
\hline 6 & $\begin{array}{l}\text { Saya mendapatkan pelatihan } \\
\text { terkait tugas- tugas yang } \\
\text { dikerjakan }\end{array}$ & 6 & 34 & 16 & 9 & 1 & 66 & 3,53 \\
\hline 7 & $\begin{array}{l}\text { Saya selalu memberikan } \\
\text { inovasi dalam setiap } \\
\text { menyelesaikan pekerjaan }\end{array}$ & 11 & 48 & 4 & 3 & 0 & 66 & 4,02 \\
\hline 8 & $\begin{array}{l}\text { Saya memiliki keterampilan } \\
\text { dan keahlian dalam bidang } \\
\text { yang saya tekuni }\end{array}$ & 11 & 41 & 11 & 3 & 0 & 66 & 3,91 \\
\hline 9 & $\begin{array}{l}\text { Saya dapat bekerjasama } \\
\text { dengan karyawan Lainnya }\end{array}$ & 25 & 37 & 4 & 0 & 0 & 66 & 4,32 \\
\hline 10 & $\begin{array}{l}\text { Saya langsung melaksanakan } \\
\text { tugas yang diberikan oleh } \\
\text { pimpinan (Manager) }\end{array}$ & 20 & 38 & 6 & 1 & 1 & 66 & 4,14 \\
\hline 11 & $\begin{array}{l}\text { Saya mampu menyelesaikan } \\
\text { pekerjaan sesuai dengan SOP } \\
\text { tanpa adanya pengawasan dari } \\
\text { pimpinan (Manager) }\end{array}$ & 10 & 47 & 7 & 2 & 0 & 66 & 3,98 \\
\hline 12 & $\begin{array}{l}\text { Saya mampu menyelesaikan } \\
\text { tugas dan fungsi pekerjaan } \\
\text { atas dasar tanggung jawab }\end{array}$ & 16 & 45 & 5 & 0 & 0 & 66 & 4,17 \\
\hline 13 & $\begin{array}{l}\text { Saya mampu memaksimalkan } \\
\text { penggunaan fasilitas dan } \\
\text { sumber daya Perusahaan }\end{array}$ & 13 & 37 & 12 & 3 & 1 & 66 & 3,88 \\
\hline 14 & $\begin{array}{l}\text { Saya mampu menggunakan } \\
\text { fasilitas dan teknologi yang } \\
\text { tersedia untuk mencapai hasil } \\
\text { pekerjaan yang maksimal }\end{array}$ & 10 & 41 & 12 & 2 & 1 & 66 & 3,86 \\
\hline 15 & $\begin{array}{l}\text { Saya patuh terhadap pimpinan } \\
\text { (Manager) dan peraturan } \\
\text { perusahaan }\end{array}$ & 14 & 45 & 7 & 0 & 0 & 66 & 4,11 \\
\hline
\end{tabular}




\begin{tabular}{|l|l|l|l|l|l|l|l|l|}
\hline 16 & $\begin{array}{l}\text { Saya merasa percaya diri } \\
\text { dengan hasil pekerjaan yang } \\
\text { saya laku }\end{array}$ & 26 & 34 & 6 & 0 & 0 & 66 & 4,30 \\
\hline Total
\end{tabular}

Berdasarkan pada tabel diatas bisa di interpretasikan bahwasanya variabel Kinerja Karyawan component treatment di PT Bintang Indokarya Gemilang Brebes baik, dimana bisa dilihat nilai total rata rata per item adalah 3,92\%. Berdasarkan pada tabel 4.5 pengukuran skor, nilai 3,92\% berada di rentang skor 3,40 - 4,19. Sehingga dapaat disimpulkan variabel kinerja karyawan di PT Bintang Indokarya Gemilang Brebes adalah baik.

\section{PENUTUP}

Berdasarkan rangkaian analisis yang telah dilakukan dalam penelitian ini, maka sesuai dengan fokus penelitian, penelitian dengan judul “Pengaruh Gaya Komunikasi Pimpinan Terhadap Kinerja Karyawan Bidang Component Treatment di PT Bintang Indokarya Gemilang Brebes " dapat disimpulkan sebagai berikut:

1. Berdasarkan. uji rata skor didapat skor 3,96 dimana skor tersebut berada di rentang 3,40 4,19. Maka dapat disimpulkan Gaya Komunikasi Pimpinan component treatment di PT Bintang Indokarya Gemilang Brebes baik.

2. Berdasarkan uji rata skor didapat skor 3,92 dimana skor tersebut berada di rentang 3,40 4,19. Maka dapat disimpulkan kinerja karyawan bidang component treatment di PT Bintang Indokarya Gemilang Brebes baik.

3. Diperoleh berikut. Nilai $t_{\text {hitung }}$ sebesar 6,418 dan mendapatkan nilai sig sebesar 0,000 . Nilai uji $t_{\text {hitung }}$ tersebut lebih besar daripada $t_{\text {tabel }}(6,418>0,2423)$ dan memiliki nilai sig. $0,000<0,05$. Maka dapat disimpulkan pada penelitian ini bahwa Variabel indenpenden Gaya Komunikasi Pimpinan berpengaruh signifikan terhadap variabel Dependen Kinerja Karyawan.

\section{DAFTAR PUSTAKA}

AA. Anwar Prabu Mangkunegara, 2007, Manajemen sumber daya manusia, Cetakan ketujuh PT. Remaja Rosdakarya, Bandung

Arikunto, S. 2002. Metodologi Penelitian Suatu Pendekatan Proposal. Jakarta: PT. Rineka Cipta. 
Arikunto, Suharsimi. 2012. Prosedur Penelitian Suatu Pendekatan Praktek. Jakarta: Rineka Cipta

Ariska Sela. 2019. Hubungan Antara agya Kepemimpinan dengan kinerja karyawan pada Perusahaan PT. Telkom Indonesia Cabang bandar Lampung . Skripsi . Fakultas Ushuludin dan Studi Agama Univertsitas Islam Negeri Bandar Lampung, 2019

Bennett, T.M. (2009), "A study of the management leadership style preferred by IT subordinates", Journal of Organizational Culture, Communications and Conflict, Vol. 13 No. 2, pp. 1-26.

Bungin, Burhan. (2005). Metode Penelitian Kuantitatif. Jakarta: Prenadamedia.

Bungin, Burhan. (2005). Metode Penelitian Kuantitatif. Jakarta: Prenadamedia.

Damayanti, E. 2014. Pengaruh Kualitas Komunikasi Kepemimpinan Terhadap Derajat Suportifitas Iklim Komunikasi Organisasi Karyawan Di Pt. Telkom Yogyakarta. Universitas Atma Jaya:Yogyakarta

Dedy,Andika. 2018. Gaya Komunikasi Pimpinan Dalam Mengembangkan Inovasi Organisasi(Studi Kasus Kepemimpinan Kepala Dinas Kependudukan Dan Pencatatan Sipil Kabupaten Padang Pariaman). Jurnal Komunikasi.

Dewi, S. P., (2012). Pengaruh Pengendalian Internal dan Gaya Kepemimpinan terhadap Kinerja Karyawan SPBU Yogyakarta (studi kasus pada SPBU anak cabang Perusahaan RB. Group). Jurnal Nominal: Volume I Nomor 1

Efendi, Onong uchjana.2009. Ilmu Komunukasi Teori Dan Praktek. Bandung: Pt Remaja Rosdakarya.

Fanny, A. 2017. Gaya Komunikasi Pimpinan Terhadap Motivasi Kinerja Karyawan Pada Pt Perusahaan Listrik Negara (PLN) Perseroarea Pelayanan Di Samarinda. Jurnal Komunikasi.

Faradhina, M.F. 2017, Pengaruh Gaya Komunikasi Pimpinan Terhadap Kinerja Karyawan Bank Tabungan Negara Kantor Kas Surabaya. Skripsi Fakultas Dakwah Dan Komunikasi. Prodi Ilmu Komunikasi. Unioversitas Islam Negeri Sunan Ampel.

Gaspersz, Vincent, 2003. Manajemen Bisnis Total - Total Quality Management. Penerbit PT. Gramedia Pustaka Utama, Jakarta.

Ghozali, I. (2011). Aplikasi analisis multivariate dengan program SPSS. Semarang: Badan Penerbit Universitas Diponegoro.

Gomes, Faustino. (2003). Manajemen Sumber Daya Manusia. Yogyakarta : Andi Ofset.

Hamdan .A.M. (2019). Pengaruh Gaya Komunikasi Pimpinan Terhadap Kinerja Karyawan Pt Indonesia Kendaraan Terminal, TBK. Skripsi. Fakultas Ilmu Sosial Dan Ilmu Politik. Prodi Ilmu Komunikasi, Universitas Brawijaya.

Hasibuan, Malayu. (2001). Manajemen Sumber Daya Manusia:Pengertian Dasar, Pengertian, dan Masalah. Jakarta: PT. Toko Gunung Agung.

Hasibuan, Malayu.(2001). Organisasi \& Motivasi. Dasar Peningkatan Produktivitas. Jakarta: BumiAksara.

Husain, fahri. (2019) Pengaruh gaya kepemimpinan dan kepuasan kinerja terhadap kinerja pegagawai pada satuan polisi pamong praja kabupaten cirebon,. Skripsi. Fakultas Ekonomi . Universitas Muhammadiyah Cirebon.

Indah, A. 2017. Pengaruh Gaya Komunikasi Pemimpin Dan Iklim Komunikasi Organisasi Terhadap Kinerja Karyawan Pt.Riau Televisi. JOM FISIP. 4(1). Ilmu Komunikasi Fakultas Ilmu Sosial Dan Ilmu Politik Bina Widya:Pekanbaru

Juarsa, E. 2016. Gaya Komunikasi Pemimpin Divisi MIS PT Tiras Santosa TBK Krian. Jurnal E-Komunikasi. 4(1). Program Studi Ilmu Komunikasi. Universitas Kristen Petra: Surabaya. 
Kriyantono, Rachmat. (2010). Teknik praktis riset komunikasi: disertai contoh praktis riset media, public relation, advertising, komunikasi organisasi, komunikasi pemasaran. Jakarta: Kencana.

Lumentut, F, G. Pantow, J, T. Waleleng, G, J. 2017. Pola Komunikasi Pemimpin Organisasi Dalam Meningkatkan Motivasi Kerja Anggota Di Lpm (Lembaga Pers Mahasiswa) Inovasi Unsrat. E-Journal Acta Diurna Komunikasi. 6(1). Universitas Sam Ratulangi Manado:Sulawesi Utara

Mandasari, W. 2017. Peningkatan Kinerja Karyawan Upaya Melalui Motivasi Kerja, Disiplin Kerja Dan Lingkungan Kerja (Studi Kasus Pada Lembaga Penyiaran Publik RRI Semarang. Jurnal Manajemen UDINUS. Program Studi Manajemen, Universitas Dian Nuswantoro SemarangSalutondok, Y. Soegoto, S. A. 2015. Pengaruh Kepemimpinan, Motivasi, Kondisi Kerja Dan Disiplin Terhadap Kinerja Pegawai Di Kantor Sekretariat DPRD Kota Sorong. Jurnal Emba. 3(3). 849-862. Fakultas Ekonomi dan Bisnis, Program Magister Manajemen Universitas Sam Ratulangi Manado:Sulawesi Utara

Mangun, Fatmala. K. (2017). Pengaruh komunikasi interpersonal antara pimpinan dan karyawan terhadap kinerja karyawan PT. Bank Sulteng Cabang Pusat. Skripsi. Malang: Universitas Brawijaya

Morrisan. (2013). Teori Kamunikasi Individu Hingga Massa Jakarta : Prenadamedia Group.

Mulyana, Deddy. 2008. Ilmu Komunikasi Suatu Pengantar. Bandung: Rosda.

Neuman, W. L. 2003. Sosial Research Method: Qualitative And Quantitative Approach. Boston: Allyn And Bacon.

Neuman, W.Lawrence. (2013). Metodologi Penelitian Sosial: Pendekatan Kualitatif dan Kuantitatif edisi 7. Jakarta: PT.Indeks.

Podsakoff, Philip M., MacKenzie, Scott B., Moorman, Robert H. and Richard Fetter (1990). "Transformational Leader Behaviors and Their Effects on Followers' Trust in Leader, Satisfaction, and Organizational Citizenship Behaviors". Leadership Quarterly. 1(2). s. $107-142$

Prakoso, Caesario. D. (2016). Pengaruh komunikasi interpersonal karyawan travel terhadap kinerja karyawan Zena Travelindo Malang. Skripsi. Malang: Universitas Brawijaya Santosa, Purbayu Budi dan ashari. 2005. Analisis statistik dengan microsoft exel dan spss. Yogyakarta: Penerbit Andi

Robbins, Stephen P.2002. Prinsip Prinsip Perilaku Organisasi, Jakarta: Erlangga.

Ruliana, Poppy. 2014. Komunikasi Organisasi: Teori dan Studi Kasus. Jakarta: Rajawali Press.

Sari, I. N, R. Hadijah, S, H. 2016. Peningkatan kinerja pegawai melalui kepuasan kerja dan disiplin kerja. Jurnal Pendidikan Manajemen Perkantoran. 1(1). 204-214. Program Studi Pendidikan Manajemen Perkantoran, Fakultas Pendidikan Ekonomi dan Bisnis, Universitas Pendidikan Indonesia:Bandung.

Sedarmayanti. 2011. Manajemen sumber daya manusia. Reformasi birokrasi dan manajemen pegawai negeri sipil, cetakan kelima, PT Refika Adita, Bandung

Sekaran, Uma and Roger Bougie. 2013. Reseacrh Method for Busines: A Skill Building Aproach, Sixt Edition. United Kingdom: John Wiley \& Spns Ltd.

Sendjaja, Djuarsa S. 2014 Teori Komunikasi. Jakarta: Universitas Terbuka.

Siagian, Sondang P. (2002). Manajemen Sumber Daya Manusia. Jakarta: PT. Bumi Aksara.

Sugiyono. (2014). Metode Penelitian Kuantitatif Kualitatif dan R\&D. Bandung: Alfabeta Sugiyono. 2005. Metode Penelitian Bisnis, CV. Alvabeta, Bandung

Sugiyono. 2007. Metode Penelitian Kuantitatif Kualitatif dan R\&D. Bandung, Alfabeta

Tubbs, S. Dan Moss, S. 2000. Human Communication, Prinsip-Prinsip Dasar. Remadja Rosdakarja : Bandung. 
Umar, Husain. 2005, riset pemasaran dan perilaku konsumen. Jakarta : PT. Gramedia Pustaka. Wijono, Sutarto.2012. Psikologi Industri Dan Organisasi. Dalam Suatu Bidang Gerak Psikolog Sumber Daya Manusia Edisi Pertama. Jakarta: Kencana Prenada Media Group.

Yukl, G. (2006), Leadership in Organizations, 6th ed., Prentice Hall, Upper Saddle River, NJ 